\title{
Global Value Chains Participation for African Countries: An Overview from UIBE GVC Index System
}

\author{
Gilhaimé Mouanda-Mouanda \\ School of International Trade and Economics, University of International Business and Economics, Beijing, China \\ Email: gilhaime@yahoo.fr
}

How to cite this paper: Mouanda-Mouanda, G. (2019) Global Value Chains Participation for African Countries: An Overview from UIBE GVC Index System. Open Journal of Business and Management, 7, 941962.

https://doi.org/10.4236/ojbm.2019.72064

Received: March 25, 2019

Accepted: April 21, 2019

Published: April 24, 2019

Copyright (อ 2019 by author(s) and Scientific Research Publishing Inc. This work is licensed under the Creative Commons Attribution International License (CC BY 4.0).

http://creativecommons.org/licenses/by/4.0/

\begin{abstract}
This paper analyzes the pattern of trade in value-added in Africa using a comprehensive database from the Research Institute for Global Value Chains at the University of International Business and Economics. We find that African economies absorb more foreign inputs in complex GVCs compared to their domestic factor content exported in simple GVCs. In addition, Southern Africa and North Africa are respectively top exporter and importer in simple GVCs while West Africa ingest the largest proportion of intermediate goods coming from abroad in complex GVCs. The secondary sector has the highest level of integration in absorbing foreign inputs. Finally, African countries, albeit weakly, are involved in downstream specialization particularly in Western and Eastern Africa.
\end{abstract}

\section{Keywords}

Global Value Chains, Upstreamness, Downstreamness, Africa

\section{Introduction}

The aim of this paper is to provide an overview of the pattern of global value chains participation in Africa. The interest in this continent comes from the fact that very few studies are exclusively devoted to it. The main reason is probably the lack of suitable and available data on trade in value-added. However, research which has been conducted so far use Eora database (e.g. [1] [2]). The Africa competitiveness report 2015 by African Development Bank and its international partners such OECD, WEF, World Bank (see [3]) relies on the value chains breadth from World Economic Forum ${ }^{1}$. Although these previous works ${ }^{1}$ Other studies are based on Trade in Value Added (TiVA) database from OECD which contains only three African countries (Morocco, South Africa and Tunisia). 
offer critical insights regarding the evolution of value chains within Africa, they are nevertheless limited.

In the context of the increased prevalence of cross-border production chains and where the participation in GVCs of developing countries is vital for their structural transformation (see e.g. [4]-[10]), it is worthwhile to understand how evolves international fragmentation of production among African countries particularly. To the best of our knowledge, the index system from Research Institute for Global Value Chains at University of International Business and Economics (UIBE) presents a better decomposition of trade in value-added. The understanding of this paradigm in Africa is conducive to implement a "new generation" of trade policies that allow to fully capture the benefits of the global production sharing.

The remainder is as follows: Section 2 briefly explains the specificity of the UIBE GVC database; Section 3 assesses the participation in simple and complex GVC; Section 4 explores the position in GVC; Section 5 is the conclusion.

\section{A Brief Explanation of UIBE GVC Index System}

Since the prevalence of international fragmentation of production, different measurements have been used to quantify trade in sequential activities. The existing indicators present some major limits (e.g. double counting problem and lack of uniformity). To overcome these drawbacks, Research Institute for Global Value Chains at University of International Business and Economics (UIBE) has developed a comprehensive set of accounting indexes to describe with accuracy the origin and destination of the factor content ${ }^{2}$. For the purpose of this study, we focus on three characteristics of the so-called UIBE GVC index system (see Appendix).

First, the index system decomposes GDP by country and by sector taking into account the forward and backward linkages as proposed by [11]. The forward linkage represents the trading relationship where a country, known as a supplier, exports domestic value-added to another country for export processing or final consumption. Similarly, the backward linkage denotes in which extent a local economy imports foreign value-added for its own consumption or for export processing.

Second, the Research Institute have decomposed total value-added into simple and complex GVC. The simple GVC stands for domestic/foreign value-added which is exports/imports and directly absorbed by trading partner. By contrast, complex GVC symbolizes domestic/foreign value-added crossing at least two borders and finally consumed abroad ${ }^{3}$. Thus, associated with the forward and backward linkages, simple and complex GVC allow identifying where value-added comes from and whether it is directly or indirectly ingested by others players along the value chain.

${ }^{2}$ The construction of this comprehensive database is not only based on the Inter-Country Input-Output (ICIO) tables and the System of National Accounts (SNA) standard, but also on the outstanding papers by [12] [13] [14] [15]. For further information, visit: http://rigvc.uibe.edu.cn/english/D_E/database_database/index.htm.

${ }^{3}$ Here, we do not take into account another form of complex value-added which also crosses borders at least twice but returns to source country for final consumption. 
The third characteristic is the production line position index. Following the works by [16] and [17], the Research team has set up two indexes showing for every single sector its position in upstream activities (Antras and Fally Upstreamness index) as well in downstream activities (Antras and Chor Downstreamness index). In clear terms, being in upstream position basically means that a country is engaged in the first stages of production and its participation in forward linkage might be higher than the participation in backward linkage. Inversely, being involved in downstream activities refers to specialization in the last steps of production and therefore the highest GVC participation comes from backward linkage. In this study, we make the difference between upstreamness and downstreamness values of each sector to get a unique figure. This latter with a positive sign implies upstream position while the negative sign points to the downstream position. For both cases, the larger the magnitude of the figure the most integrated a country/sector.

\section{Simple and Complex GVC within African Countries}

The analysis of Figure 1 shows that the supply side of value chains in simple GVC within African countries accounts for on average 12 percent while the demand side of value chains is 10 percent on average. By contrast, the tendency is reversed when it comes to complex GVC: it clearly appears that forward participation stands at 7 percent on average whereas backward participation is on average 16 percent.

On the whole, this suggests that the share of domestic value-added to export for direct partners is larger than the proportion of imported foreign inputs consumed in Africa. On the other hand, given that the percentage of foreign value-added exceeds the one of domestic inputs involved in complex activities, the

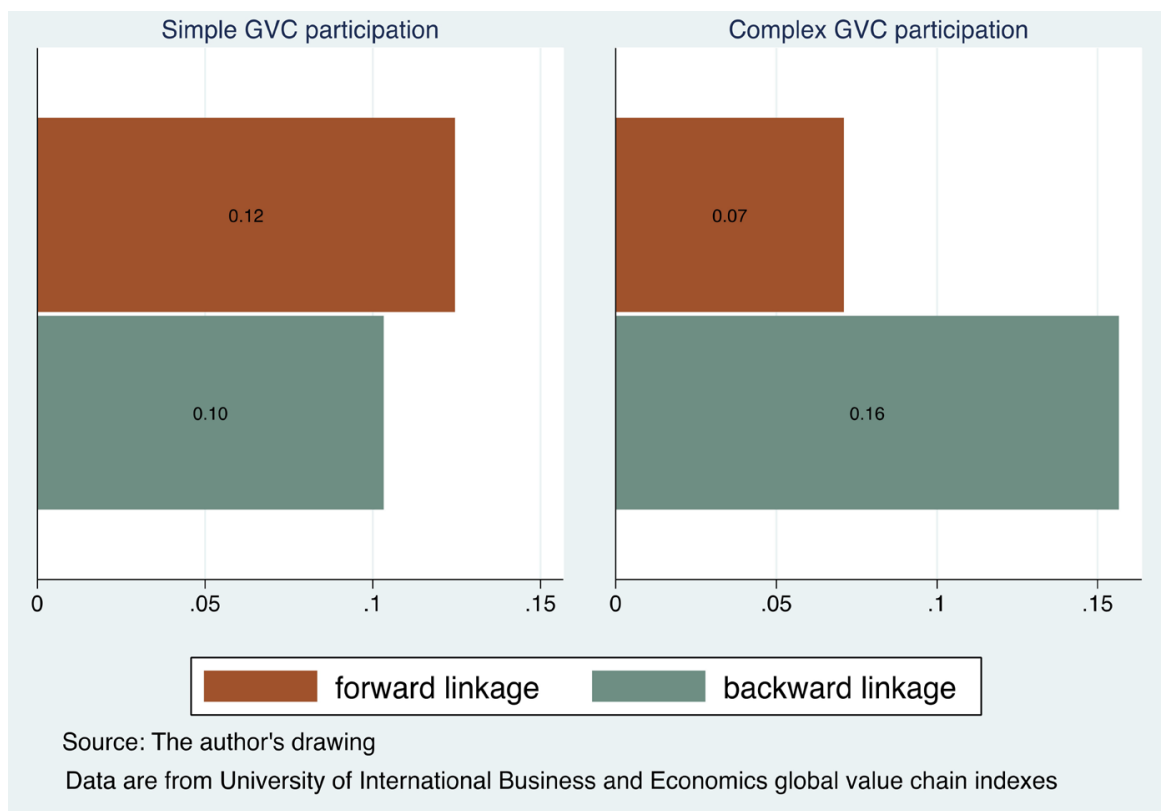

Figure 1. GVC participation for African countries (full sample). 
continent is used as an export processing platform for intermediate goods coming from abroad.

\subsection{Simple GVC within African Regions ${ }^{4}$}

As shown in Figure 2, Southern Africa is the most engaged in forward linkage with a participation of $15 \%$ on average. North Africa is second in the supply side of value chains (13\%). West and East Africa are involved in domestic value-added to export toward direct partners respectively with $11 \%$ and $10 \%$. Central Africa is the least engaged in simple GVC (7\%).

For backward participation, we observe that North Africa with $12 \%$ is the first importer of foreign inputs. The level of involvement of West and Central Africa is $11 \%$. Southern Africa exhibit a participation of $10 \%$ and East Africa has the lowest engagement (9\%).

\subsubsection{Simple GVC by Country within Regions}

In North Africa (Figure 3), the highest participation (20\%) in domestic value-added to export toward direct partners is observed in Tunisia. Morocco is second with $11 \%$ and the least involved is Egypt (8\%). By contrast, this latter imports the largest share of foreign inputs (14\%) that is consumed domestically. Morocco and Tunisia have the same level of engagement (12\%) in backward linkage.

In West Africa (Figure 4), Togo has the highest participation (23\%) in exporting domestic value-added used by direct partners. Next, Senegal and Cote d'Ivoire display respectively $16 \%$ and $14 \%$. The participation of Ghana in the simple supply side of value chains stands at 11 percent. Other economies like

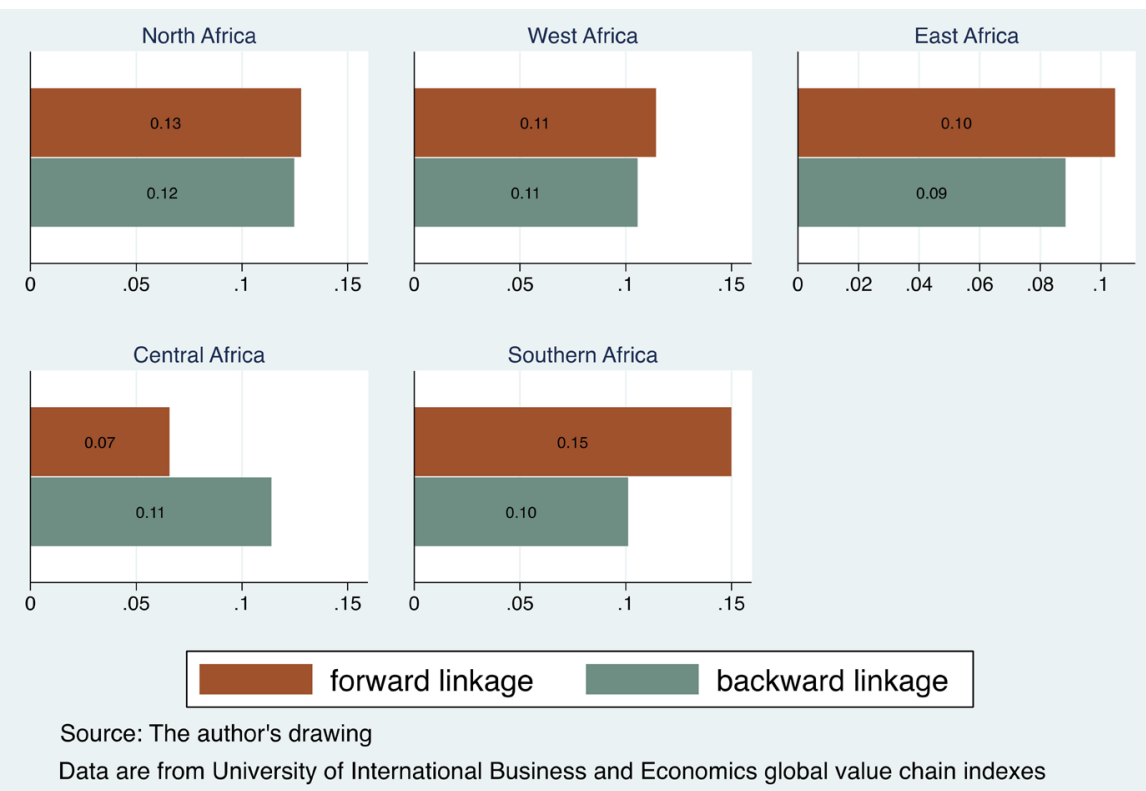

Figure 2. Simple GVC participation by region.

${ }^{4}$ The available African countries in the UIBE-GVC database are classified by regions in accordance with African Development Bank: https://www.afdb.org/en/countries/. 


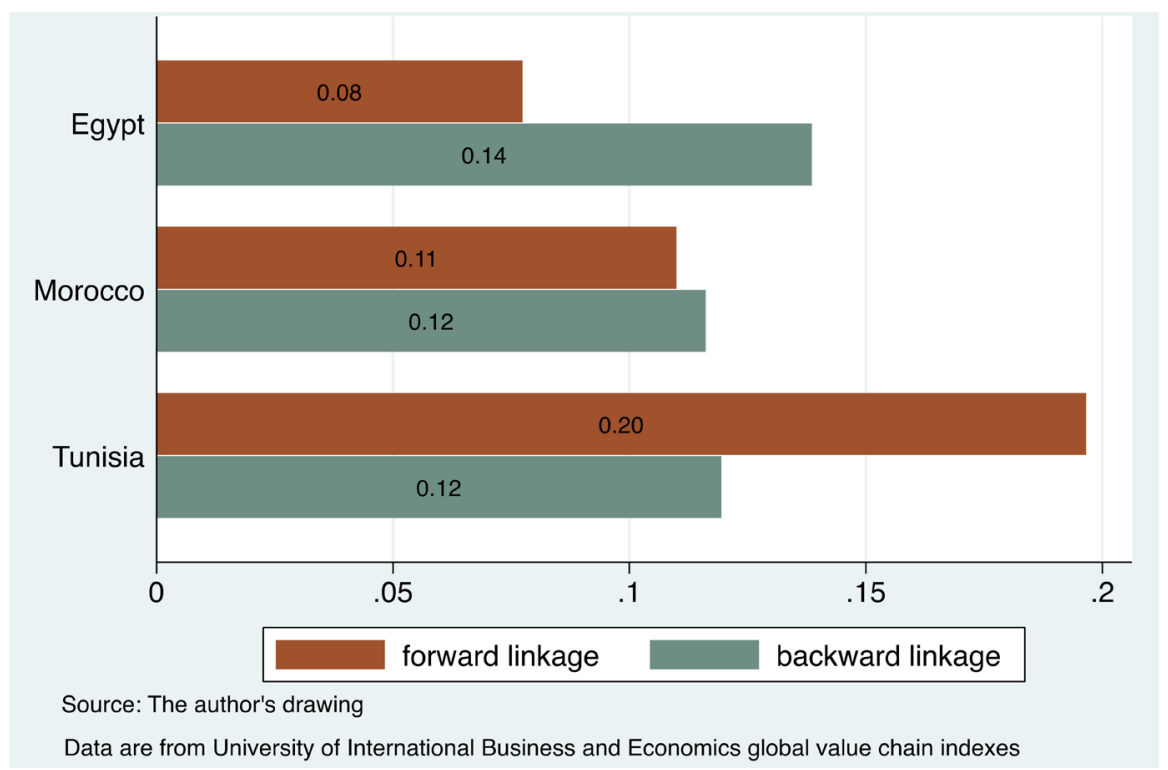

Figure 3. Simple GVC participation by country (North Africa).

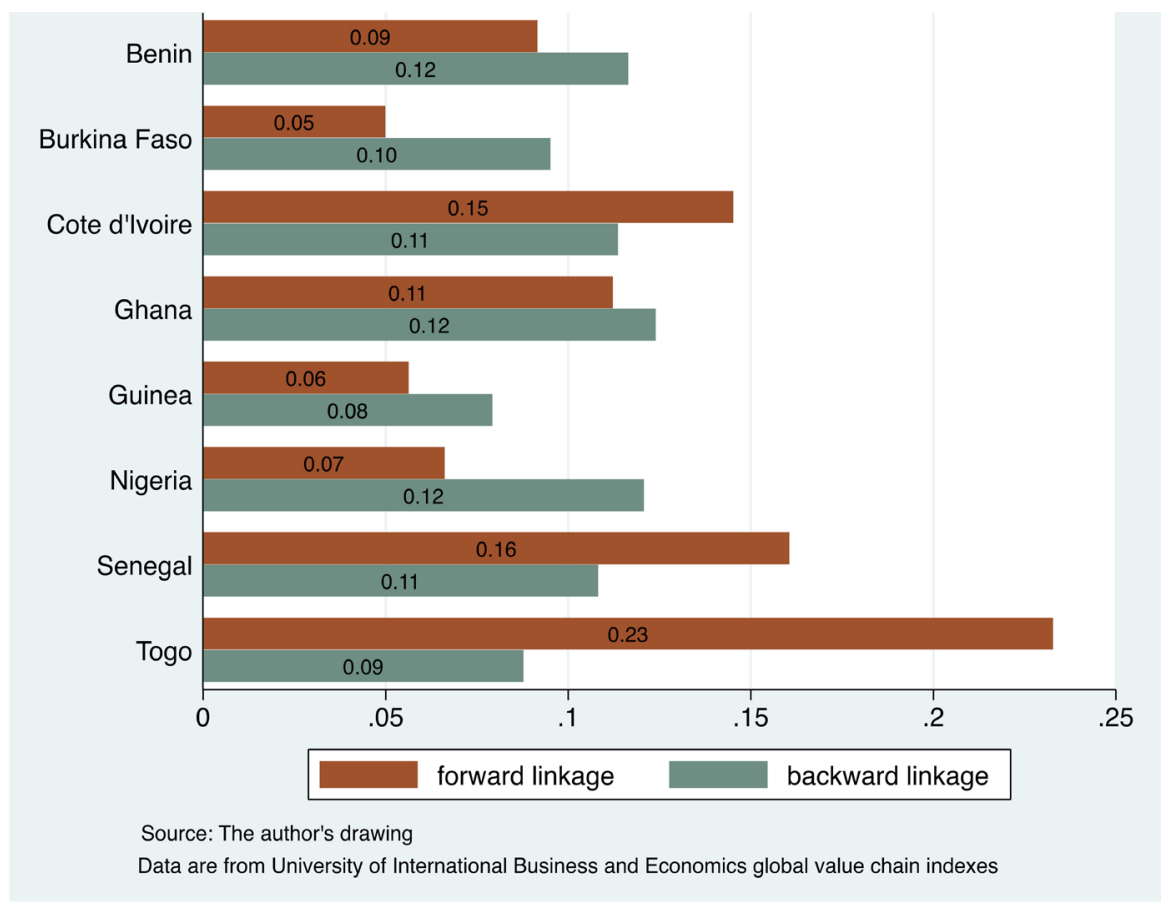

Figure 4. Simple GVC participation by country (West Africa).

Benin, Nigeria, Guinea and Burkina Faso export less than 10\% of their domestic factor content toward direct importers. On the other hand, the direct consumption of imported foreign intermediate goods is more important (12\%) in Benin, Ghana and Nigeria. Senegal and Cote d'Ivoire domestically absorb $11 \%$ of foreign inputs while Burkina Faso ingests 10\%. Finally, The proportion of Guinea and Togo is insignificant.

In East Africa (Figure 5), Tanzania (13\%) followed by Kenya and Uganda (both 12\%) are the most engaged in domestic factor content to exports absorbed 
by direct partners. The involvement of Ethiopia and Rwanda is inferior to 10 percent. On the contrary, the highest share of foreign value-added and consumed domestically goes to Ethiopia and Tanzania (both 10\%).

In Central Africa (Figure 6), the engagement of Cameroon is only 7\%. By contrast, the Cameroonian economy absorbs directly 11 percent of the foreign inputs.

In Southern Africa (Figure 7), Mauritius and Madagascar are the largest exporters of domestic factor content (20\%) directly consumed by importers. The second largest exporter is Namibia with 19 percent followed by Zambia and

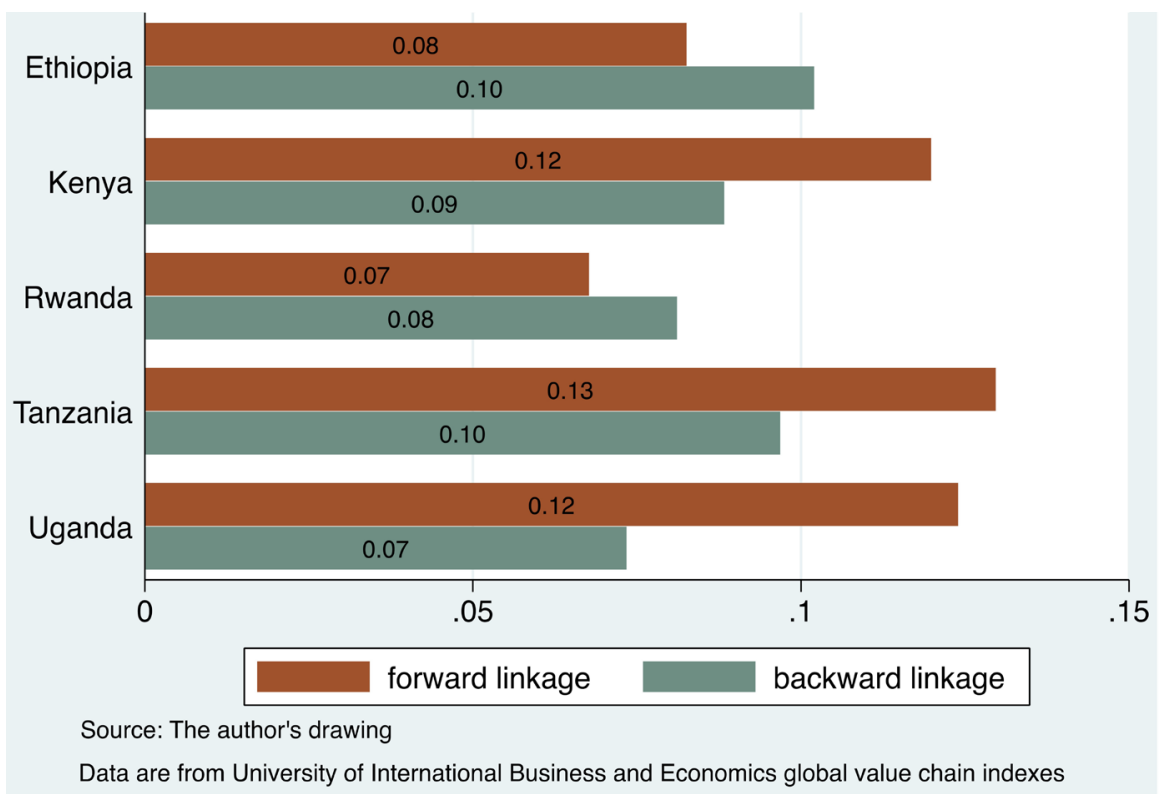

Figure 5. Simple GVC participation by country (East Africa).

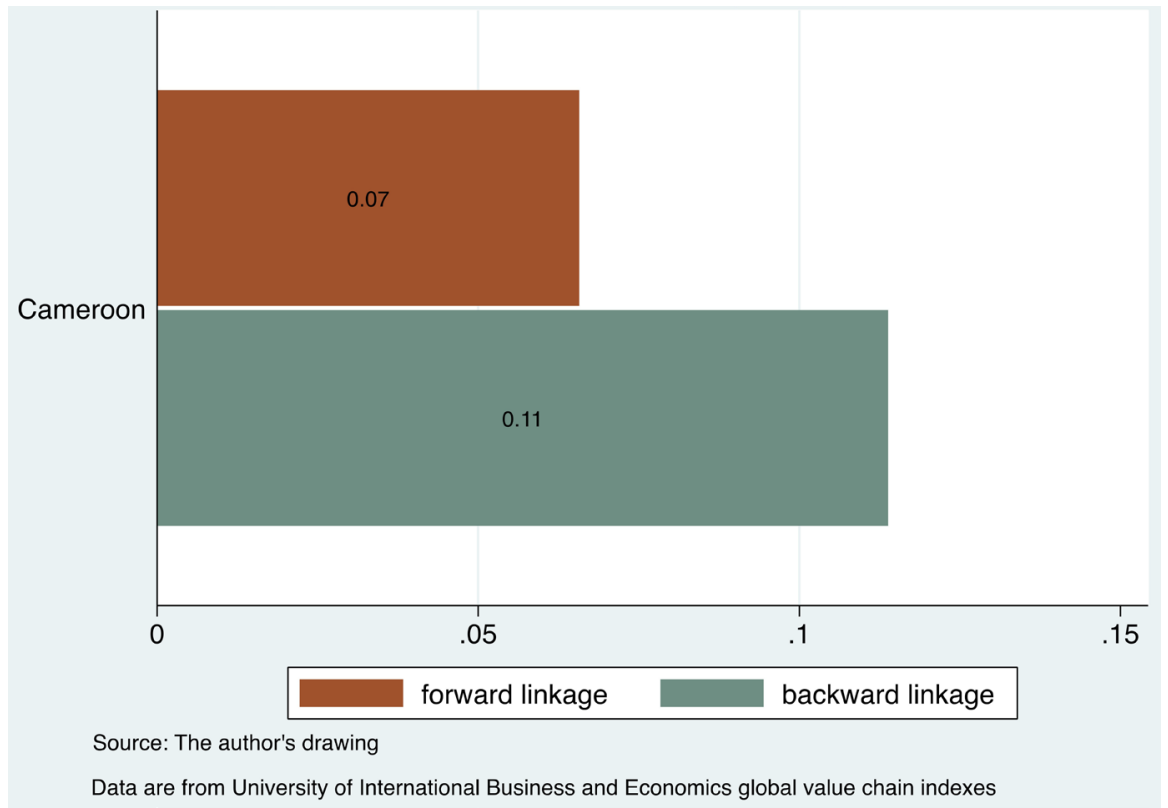

Figure 6. Simple GVC participation by country (Central Africa). 


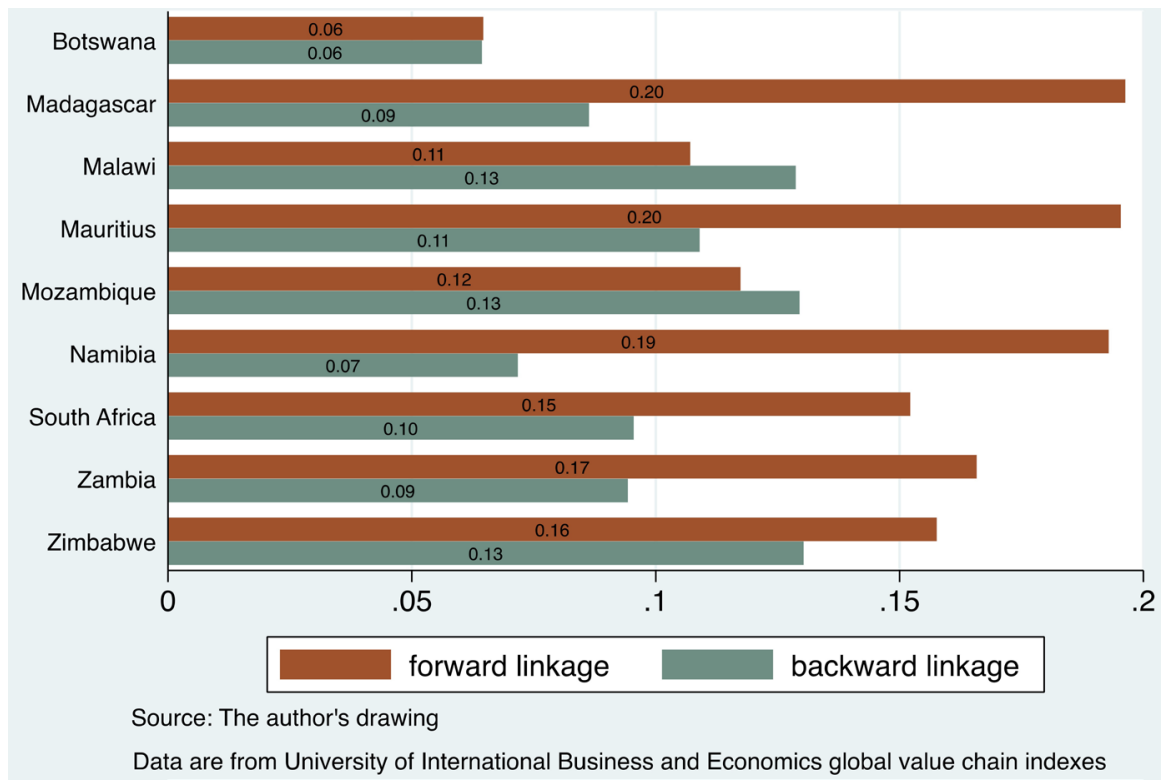

Figure 7. Simple GVC participation by country (Southern Africa).

Zimbabwe with 17 percent. Other countries with a participation greater than $10 \%$ in domestic value-added to export toward direct partner are South Africa, Mozambique and Malawi. Botswana is the least involved in the simple supply side of value chains.

On the side of backward participation, we notice that Malawi, Mozambique and Zimbabwe absorb the highest percentage of foreign inputs (13\%) for their domestic consumption. Mauritius and South Africa import respectively 11 and 10 percents. The demand side of value chain within Madagascar, Zambia, Namibia and Botswana are below 10\%.

\subsubsection{Simple GVC by Sector within Regions}

\section{North Africa}

Figure 8 shows that the tertiary sector displays the highest participation in domestic value-added to export for direct consumption (14\%). The detailed sectoral analysis reveals that the prevailing trend comes from the air transportation sector and others sectors related to transportation. The secondary sector has also an important share of simple forward linkage (13\%), particularly in the sectors of ferrous metals, machinery equipment, and petroleum coal products.

On the side of backward linkage, the secondary sector uses the largest proportion of imported foreign inputs (15\%). The driving sectors are motor and vehicles parts, electronic and transport equipments. Likewise, the tertiary sector domestically absorbs $13 \%$ of foreign intermediate goods mainly in the sectors of water transportation, recreational and other services.

The primary sector in North Africa compared to the two previous is the least involved in GVC. But the forward linkage (11\%) is higher than the backward participation (6\%). The sectors chiefly exporting value-added are oil and gas, forestry and minerals. 


\section{West Africa}

As shown in Figure 9, the second sector has the highest participation in simple forward linkage (13\%) particularly in metals and ferrous metals industries. By contrast, the tertiary sector is the most engaged in simple backward participation, i.e., countries within this region import the largest proportion of foreign inputs consumed domestically. The sectors concerned are: air transportation, water transportation, electricity and other transportation.

We observe also that the primary sector in West Africa is the least involved in both forward (8\%) and backward GVC participation (6\%).

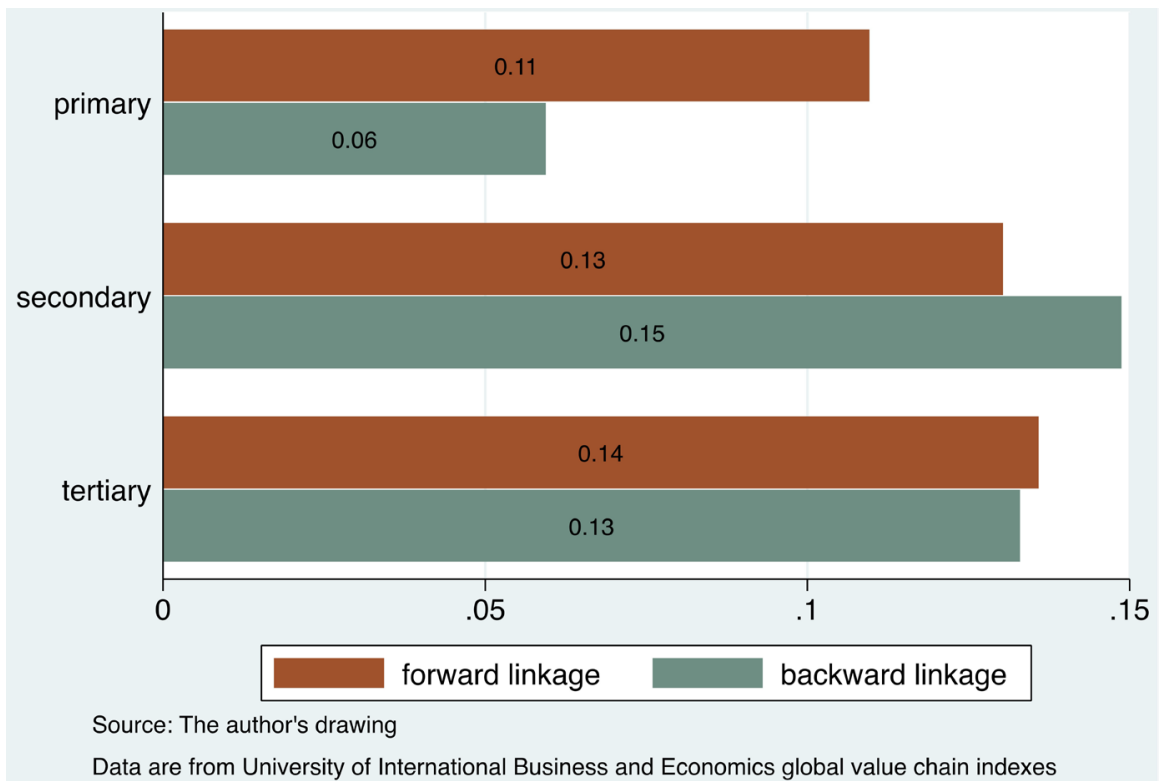

Figure 8. Simple GVC participation by sector (North Africa).

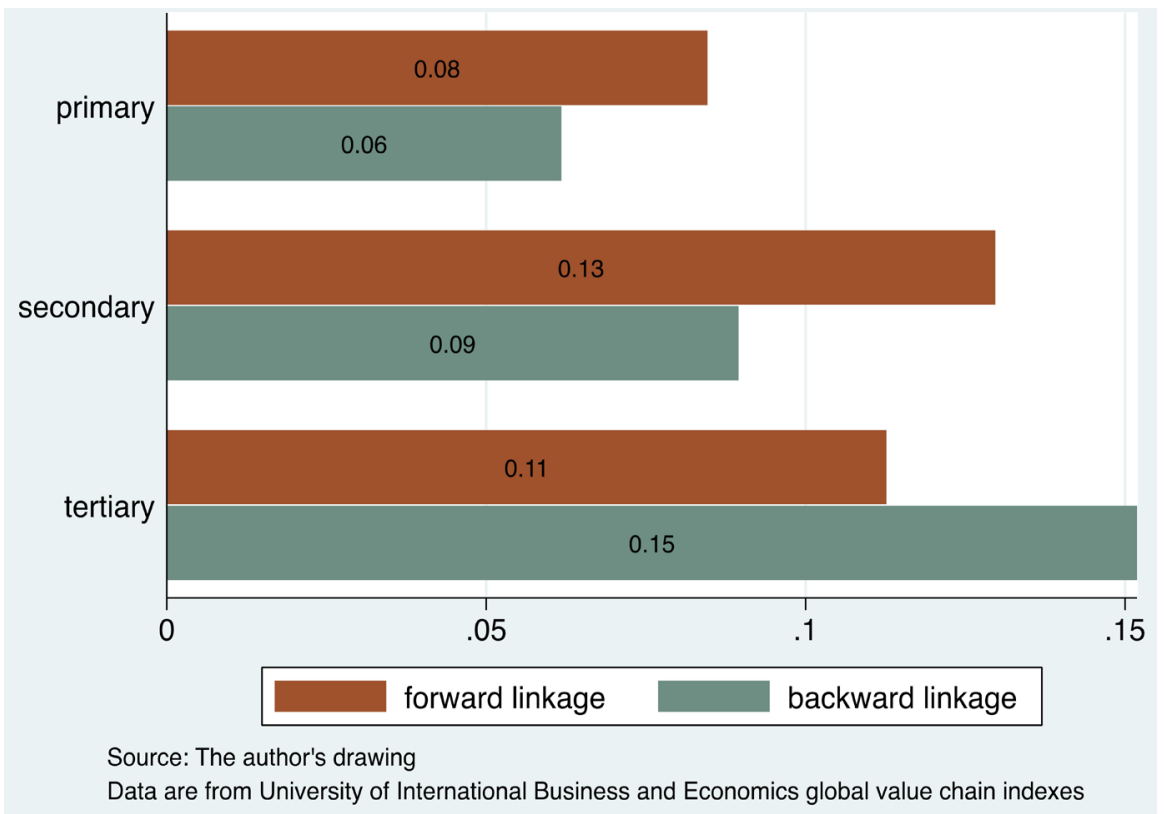

Figure 9. Simple GVC participation by sector (West Africa). 


\section{East Africa}

Figure 10 shows that the tertiary sector among eastern African countries exports the largest percentage of domestic value-added directly absorbed abroad (12\%) in the sectors of air transportation, insurance and gas manufacture and distribution. Similarly, this tertiary sector consumes the highest proportion of inputs coming from foreign countries (12\%). The sectors mostly engaged in backward participation are water transportation, air transportation and electricity.

The secondary sector exports more domestic factor content directly used by partners (11\%) than it imports for local consumption (9\%). Metals, ferrous metals, manufactures, and petroleum coal products are the most important sectors in forward linkage.

The percentage of the primary sector in forward and backward linkages are insignificant compared to the tertiary and secondary sectors.

\section{Central Africa}

Figure 11 unveils that the tertiary sector displays the largest participation in exporting domestic value-added used by the direct partners (9\%). The most dynamic sectors are: air transportation and insurance. The primary (mainly in cotton and wool production) and secondary (in petroleum coal products and metals nec ${ }^{5}$ ) sectors represent both 5 percent of factor content to export. With respect to backward linkage, the tertiary sector absorbs the largest percentage of imported foreign inputs (18\%) in gas manufacture and distribution, water and water transportation water transportation. Once more, the secondary (mainly in leather products, textiles and beverages and tobacco products) and primary (in minerals nec and fishing) sectors are the least integrated in the demand side of value chain respectively by $9 \%$ and $5 \%$.

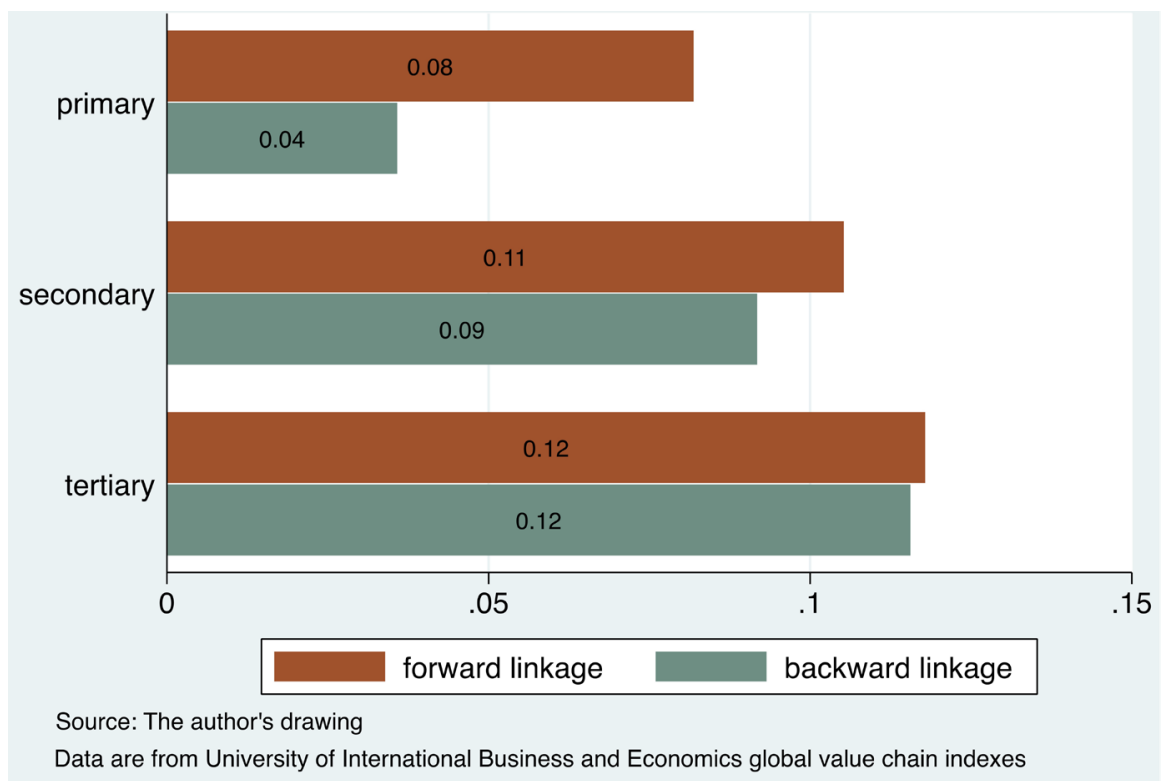

Figure 10. Simple GVC participation by sector (East Africa).

${ }^{5}$ nec means "not elsewhere classified". 


\section{Southern Africa}

The analysis of Figure 12 shows that the three main sectors are strongly involved in forward participation. We observe that the secondary sector exports $16 \%$ of domestic factor content directly absorbed abroad particularly within metals, ferrous metals and chemical rubber plastic products. The primary (minerals, cotton and wool production, and oil and gas) and tertiary (gas manufacture and distribution, air transportation and water transportation) have the same percentage of engagement (14\%).

For the backward linkage, the tertiary sector ingests the highest proportion of

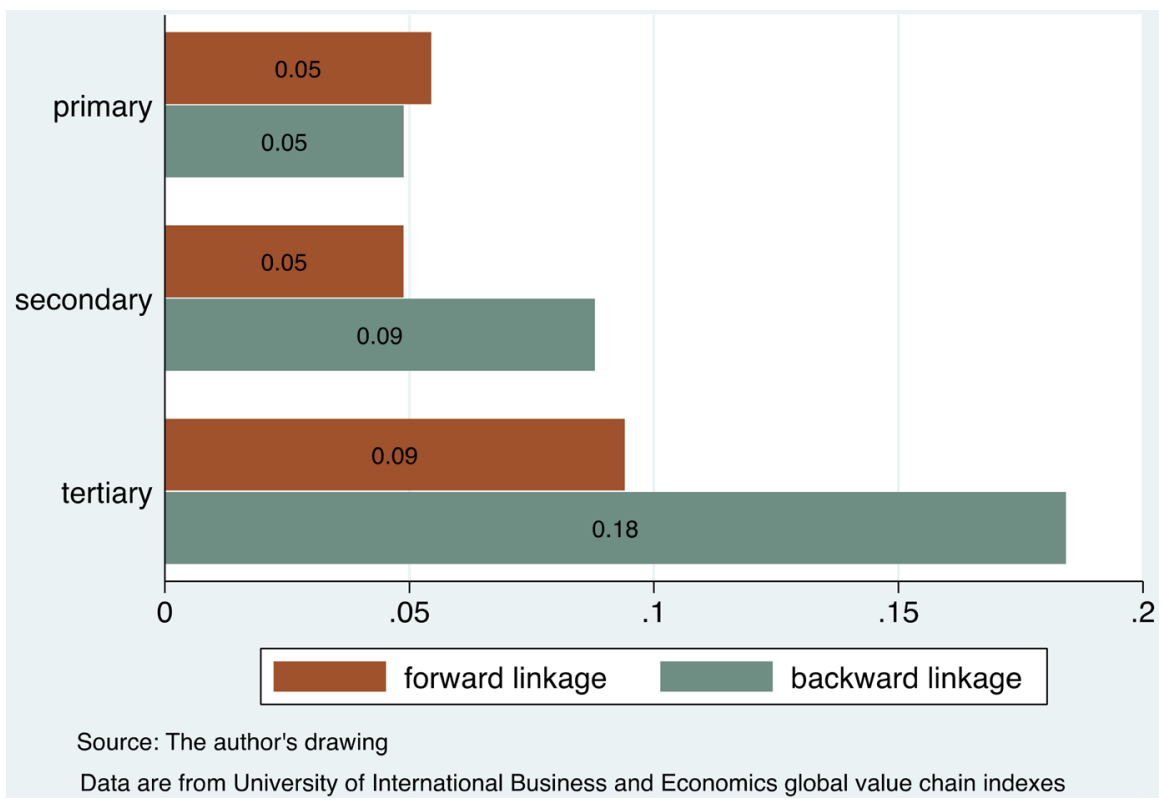

Figure 11. Simple GVC participation by sector (Central Africa).

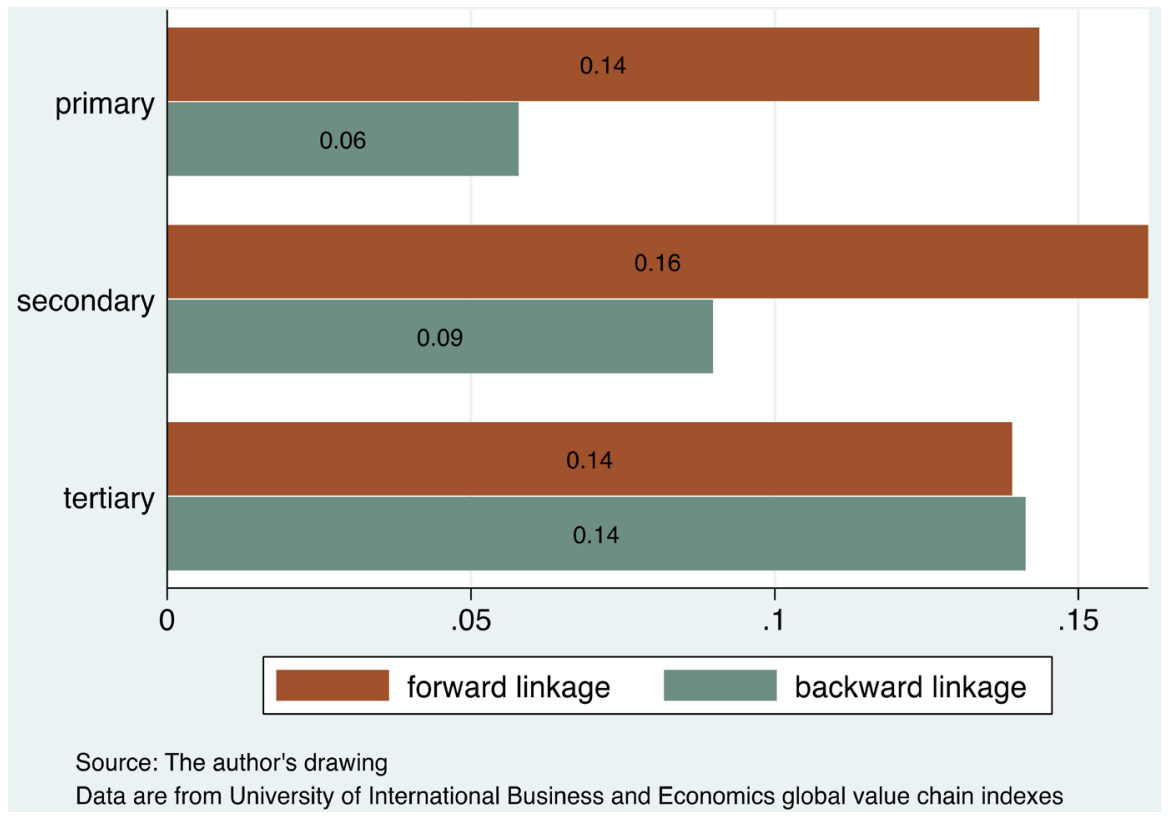

Figure 12. Simple GVC participation by sector (Southern Africa). 
imported foreign inputs (14\%) in the sectors such as water transportation, air transportation and other activities related to transportation. The secondary and primary industries absorb directly $9 \%$ and $6 \%$ of value-added coming from abroad.

\subsection{Complex GVC within African Regions}

Figure 13 clearly shows that Africa, on the whole, is chiefly an importer of foreign value-added that crosses more than two borders. The most involved region is West Africa with $17 \%$ followed by North Africa importing 16\%. Southern Africa absorbs $16 \%$ and the participation of East Africa is 14 percent. Central Africa has the lowest engagement in complex GVC (10\%).

We also notice that the engagement in complex forward linkage is nearly insignificant for most African regions except Southern Africa that is 9 percent.

\subsubsection{Complex GVC by Country within Regions}

The analysis of Figure 14 unveils that among the sampled North Africa's countries, Tunisia with $17 \%$ absorbs the largest proportion of imported foreign inputs involved in complex GVCs. Moreover, the country provides $11 \%$ of their domestic value-added to complex GVC activities. Egypt and Morocco use 15\% of foreign value-added that straddles at least two borders but their complex forward participation is meaningless.

In West Africa, all countries are poorly engaged in complex forward value chains (Figure 15). However, they consume an important share of intermediate goods coming from abroad in the framework of complex GVC trade. Benin is the most involved with $28 \%$. There are also Togo (25\%) and Ghana (22\%).

A similar trend is noticed within East Africa (Figure 16). The participation in complex demand side of value chains is the highest in Kenya (23\%). Tanzania
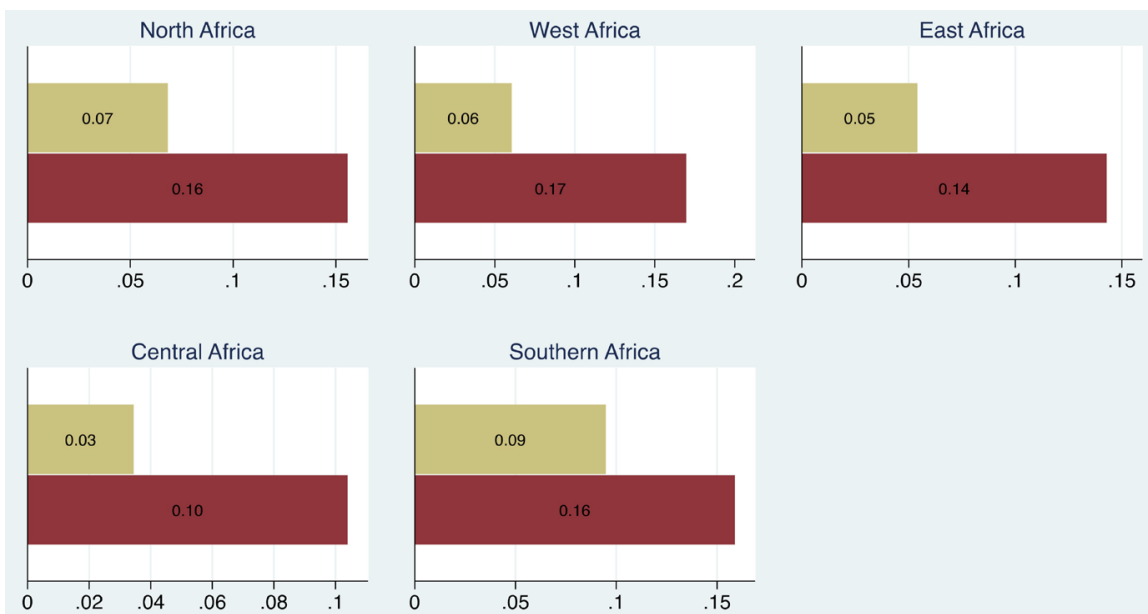

\section{forward linkage}

backward linkage

Source: The author's drawing

Data are from University of International Business and Economics global value chain indexes

Figure 13. Complex GVC participation by region. 


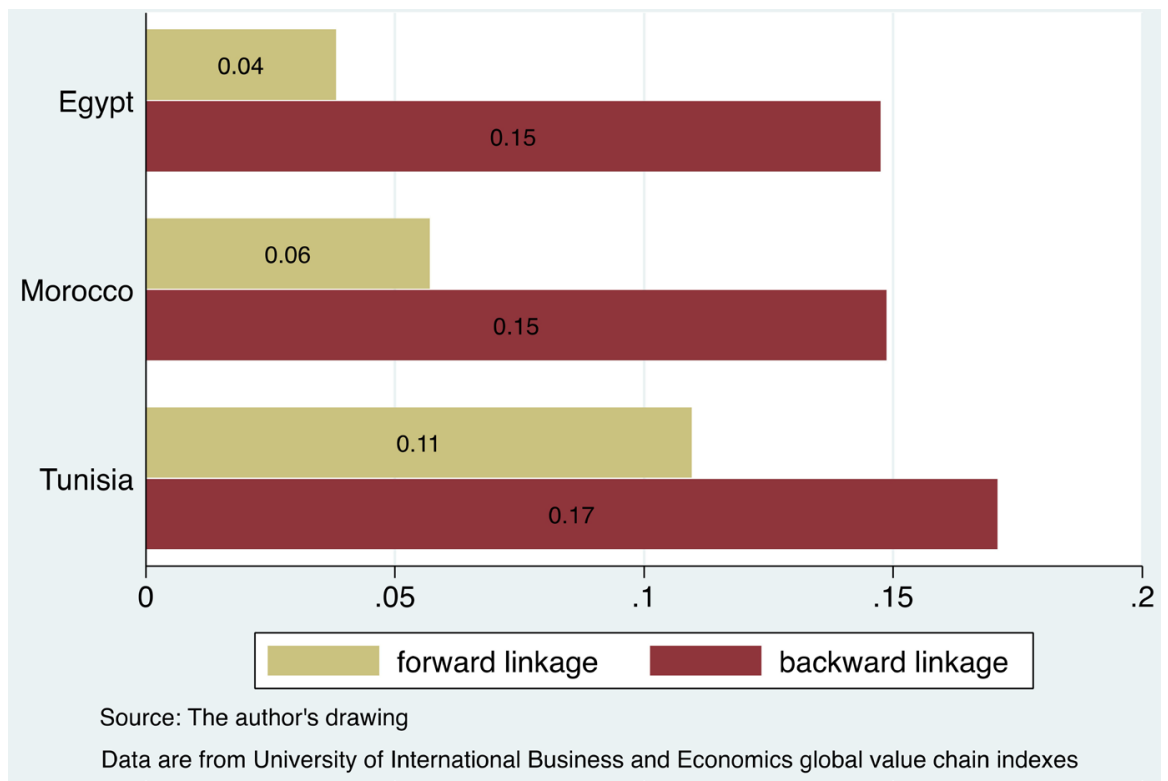

Figure 14. Complex GVC participation by country (North Africa).

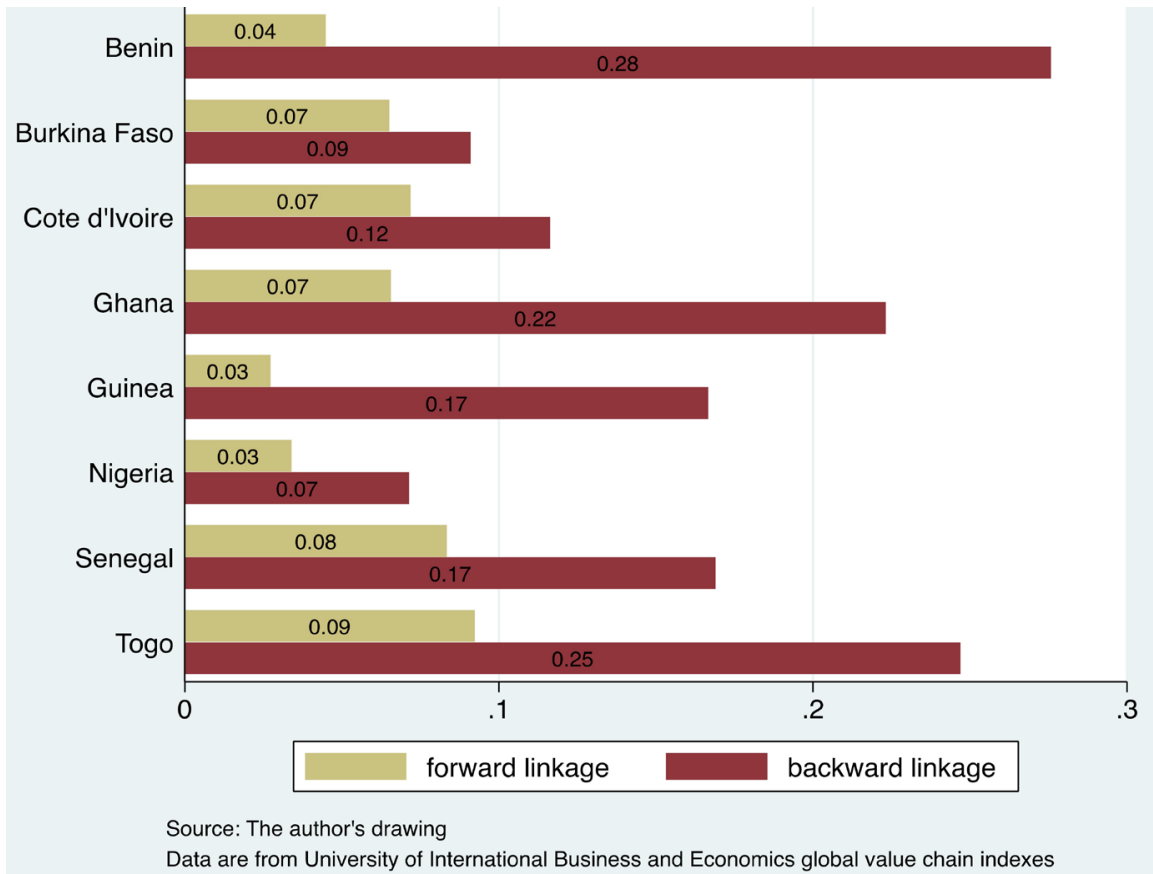

Figure 15. Complex GVC participation by country (West Africa).

and Uganda display 13\% while Rwanda and Ethiopia respectively account for $12 \%$ and $11 \%$.

In Central Africa (Figure 17), the engagement of Cameroon in supplying value-added that crosses at least two borders is very low (3\%). Conversely, the share of foreign inputs that straddles minimum two borders and finally consumed in the domestic economy is 10 percent.

In Southern Africa (Figure 18), Mauritius ingests the largest percentage (22\%) of foreign inputs involved in complex GVCs. Madagascar is second with $20 \%$. 


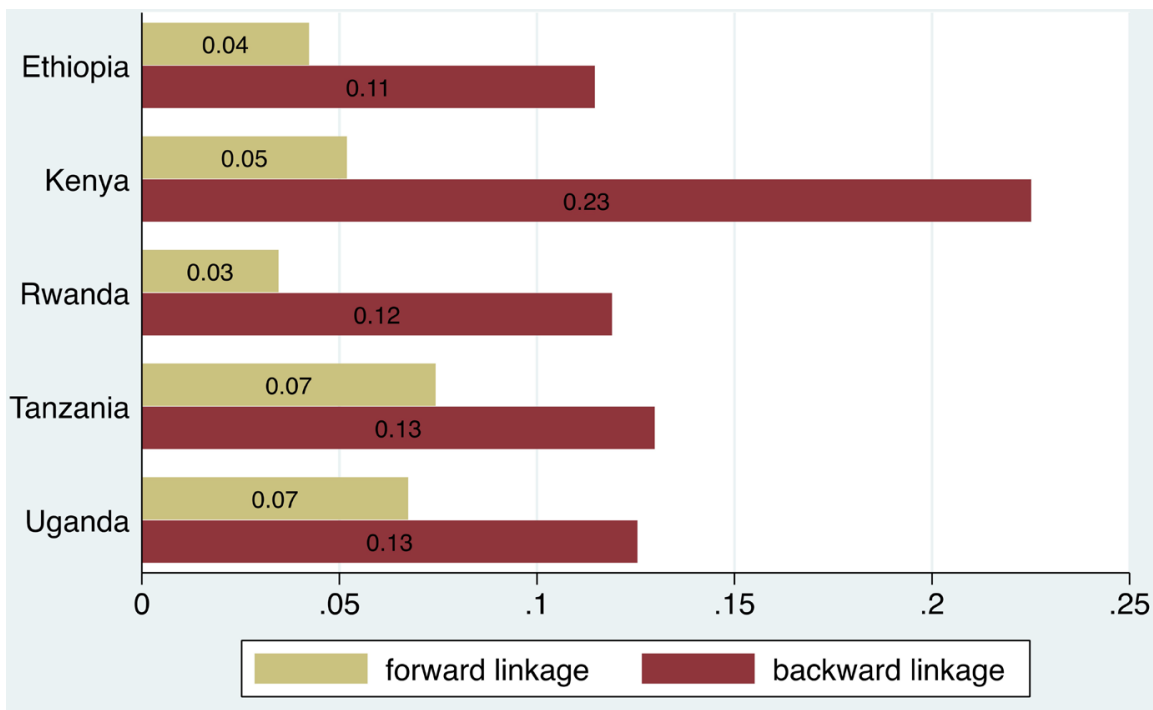

Source: The author's drawing

Data are from University of International Business and Economics global value chain indexes

Figure 16. Complex GVC participation by country (East Africa).

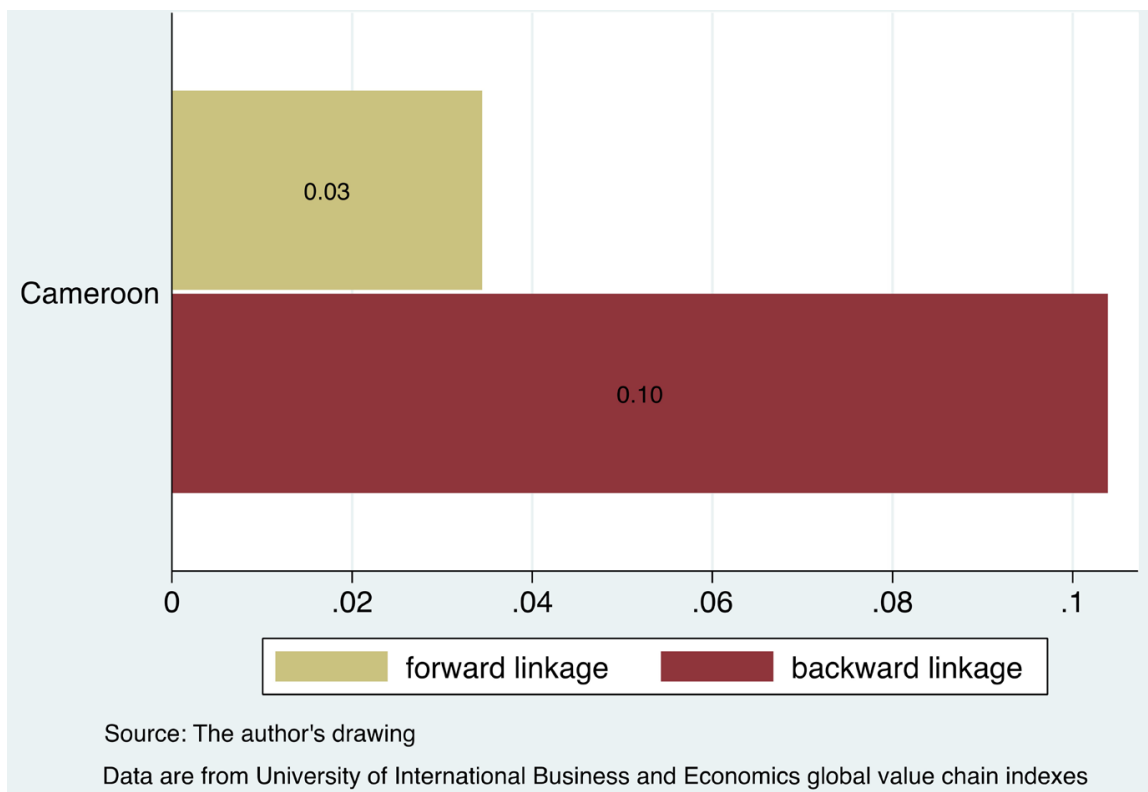

Figure 17. Complex GVC participation by country (Central Africa).

Mozambique and Zambia absorb 17\%. South Africa with $10 \%$ lags behind Botswana and Malawi (15\% for both) and Namibia (14\%). On the other hand, within Southern Africa the highest participation in complex supply side of value chains is observed in Zambia (18\%) and Zimbabwe (12\%).

\subsubsection{Complex GVCs by Sector within Regions}

\section{North Africa}

Figure 19 reveals that the secondary sector (e.g. ferrous metals, machinery and equipment, and metals) is the most engaged in complex demand side of value chains $(21 \%)$. The primary sector (e.g. coal and forestry) has also an important 


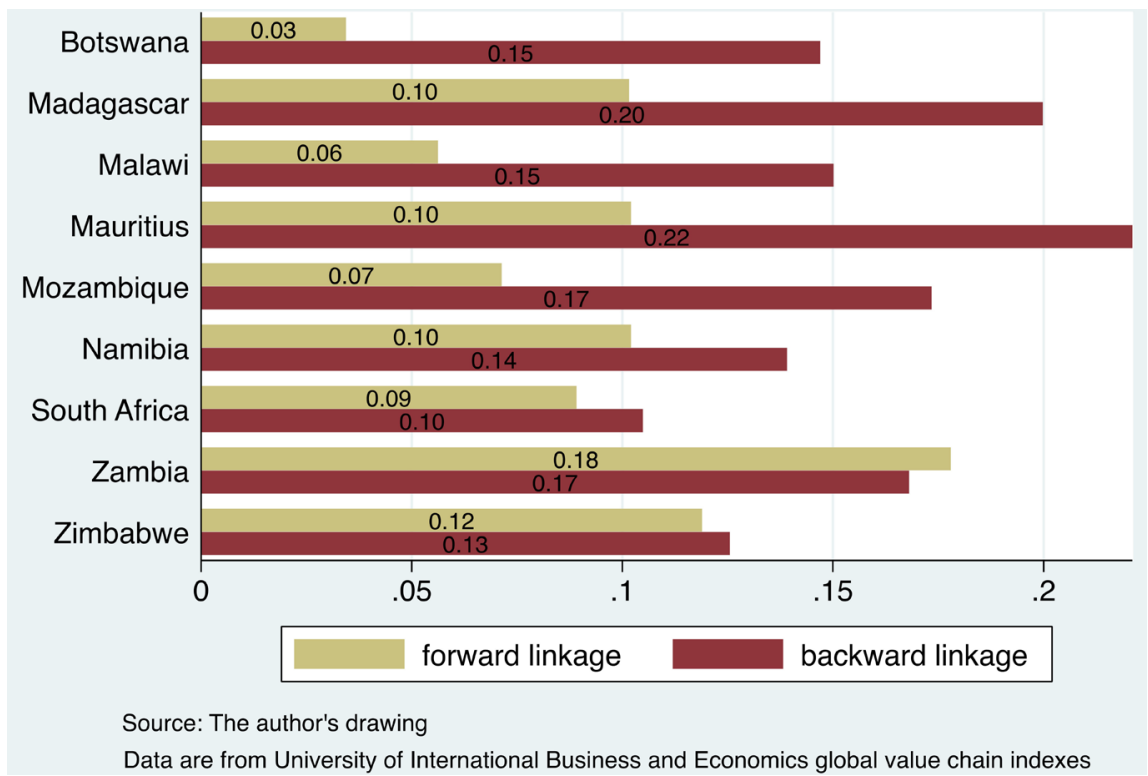

Figure 18. Complex GVC participation by country (Southern Africa).

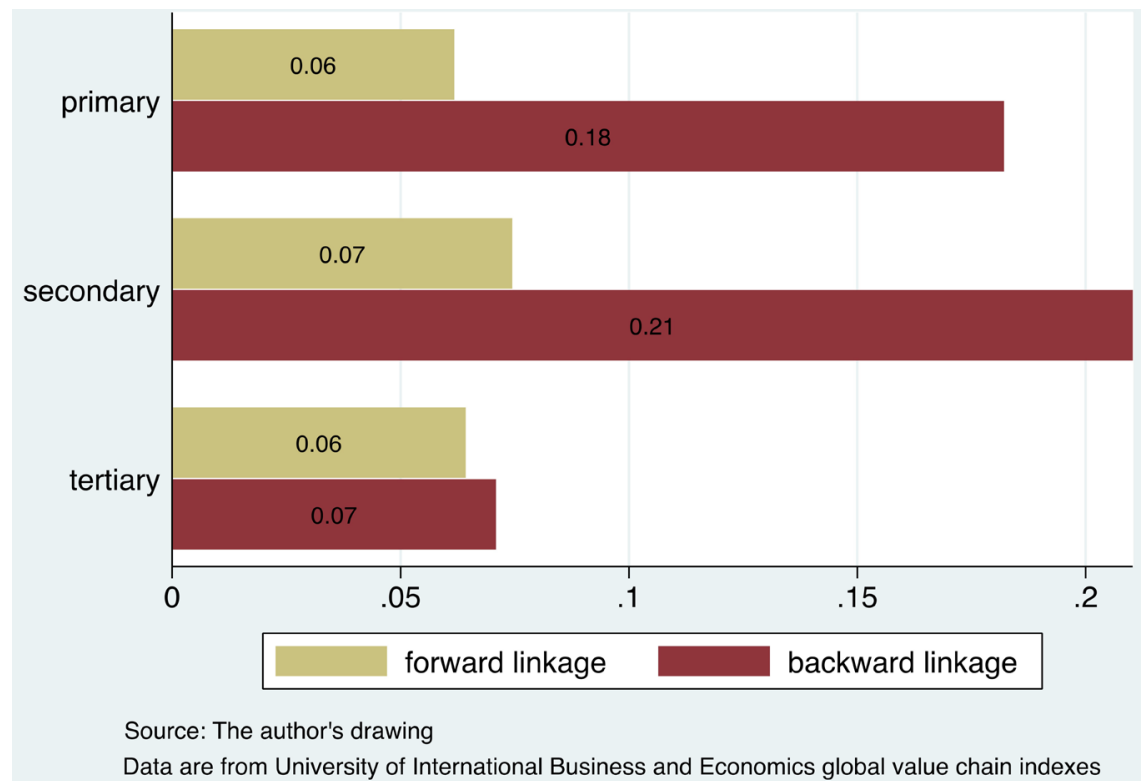

Figure 19. Complex GVC participation by sector (North Africa).

percentage (18\%). The tertiary sector is the least involved in complex GVC trade.

\section{West Africa}

Figure 20 shows that the secondary sector (e.g. motor vehicles and parts, electronic equipment and petroleum coal products) ingests the highest share of foreign value-added in complex GVC trade (24\%). Another high participation (16\%) comes from the primary sector (e.g. coal, oil and gas, and minerals). The engagement of the tertiary sector is simply insignificant.

\section{East Africa}

In Figure 21 we observe that the level of participation in complex backward linkage is similar (18\%) for the primary sector (e.g. coal, and oil and gas) and the 


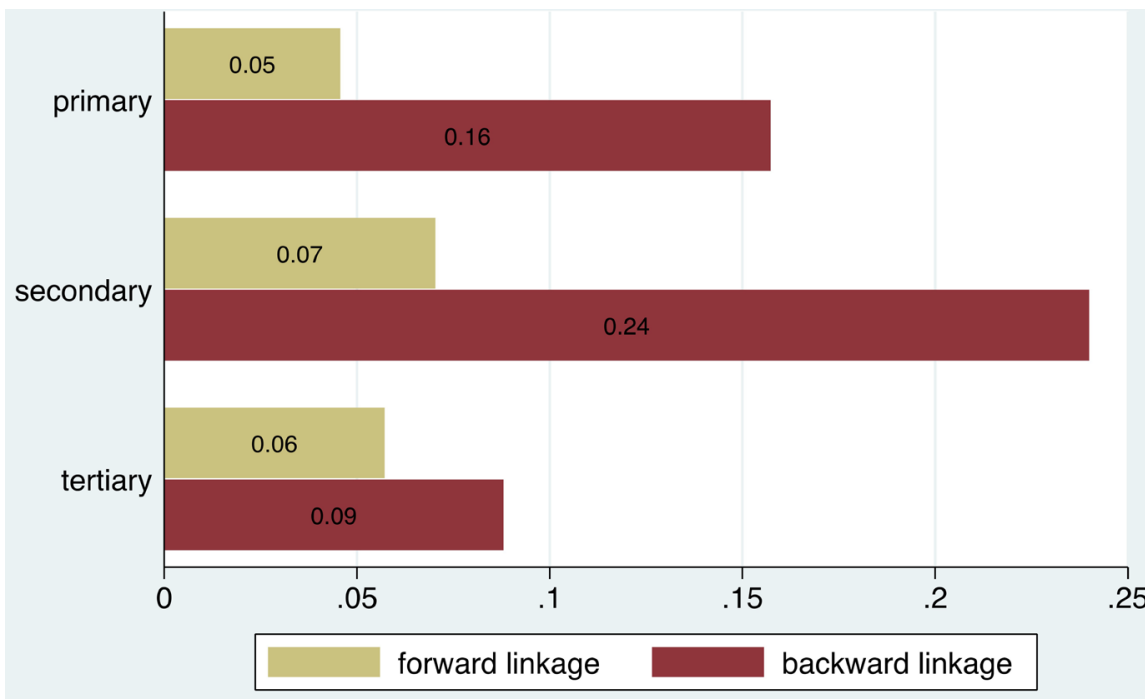

Source: The author's drawing

Data are from University of International Business and Economics global value chain indexes

Figure 20. Complex GVC participation by sector (West Africa).

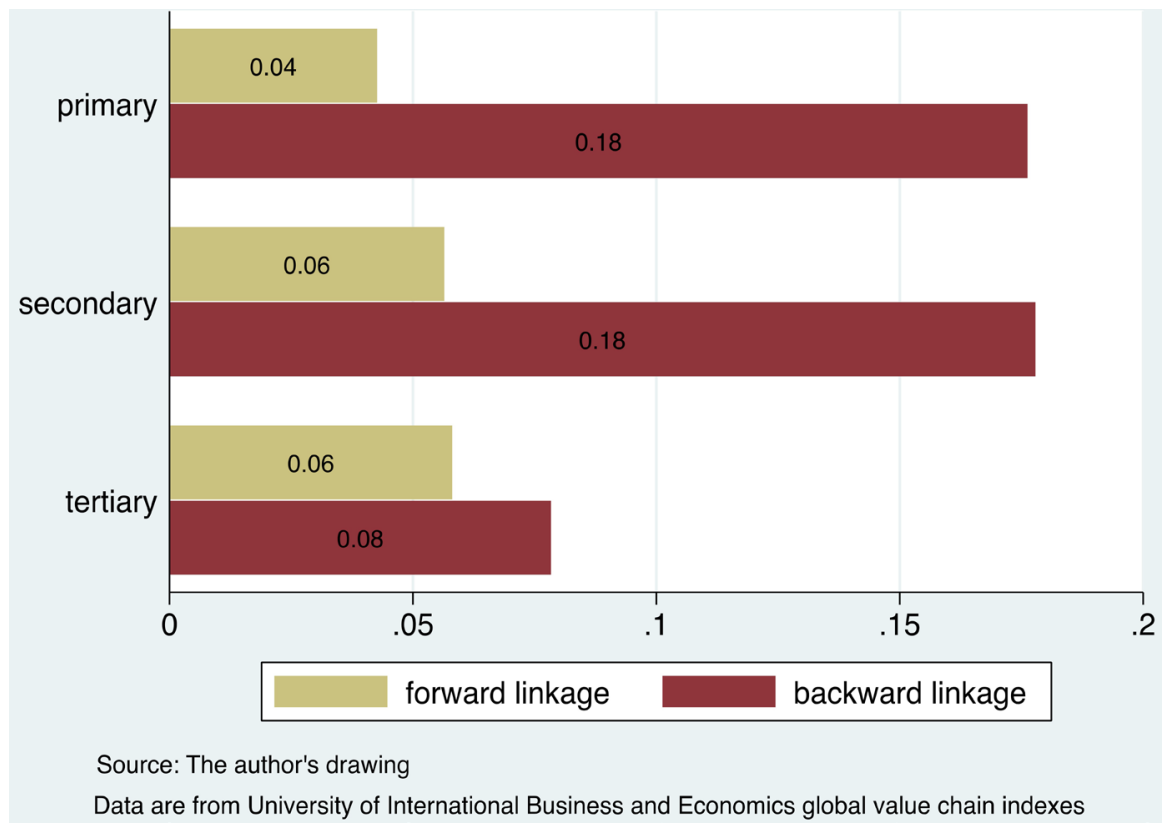

Figure 21. Complex GVC participation by sector (East Africa).

secondary sector (petroleum coal products, ferrous metals and metals). The tertiary sector still lags behind compared to the two previous ones.

\section{Central Africa}

The sectoral analysis among the economy of Cameroon in Central Africa (Figure 22) points out the prominence of the primary sector (e.g. coal and minerals) consuming $15 \%$ of foreign inputs involved in complex GVC trade. The secondary sector (e.g. metal products, ferrous metals and mineral products nec) absorbs $12 \%$ of intermediate goods coming from abroad in complex GVC. The engagement in the tertiary sector is insignificant. 


\section{Southern Africa}

The percentage of intermediate goods coming from indirect partners to be consumed in the domestic economies accounts for 21 percent (Figure 23) in the secondary sector (transport equipment, ferrous metals, petroleum coal products, and mineral products). The primary sector (coal, cotton and wool production, and oil and gas) is the second consumer of foreign inputs (18\%). On the whole, the engagement in the tertiary sector is insignificant (supply and demand sides of value chain).

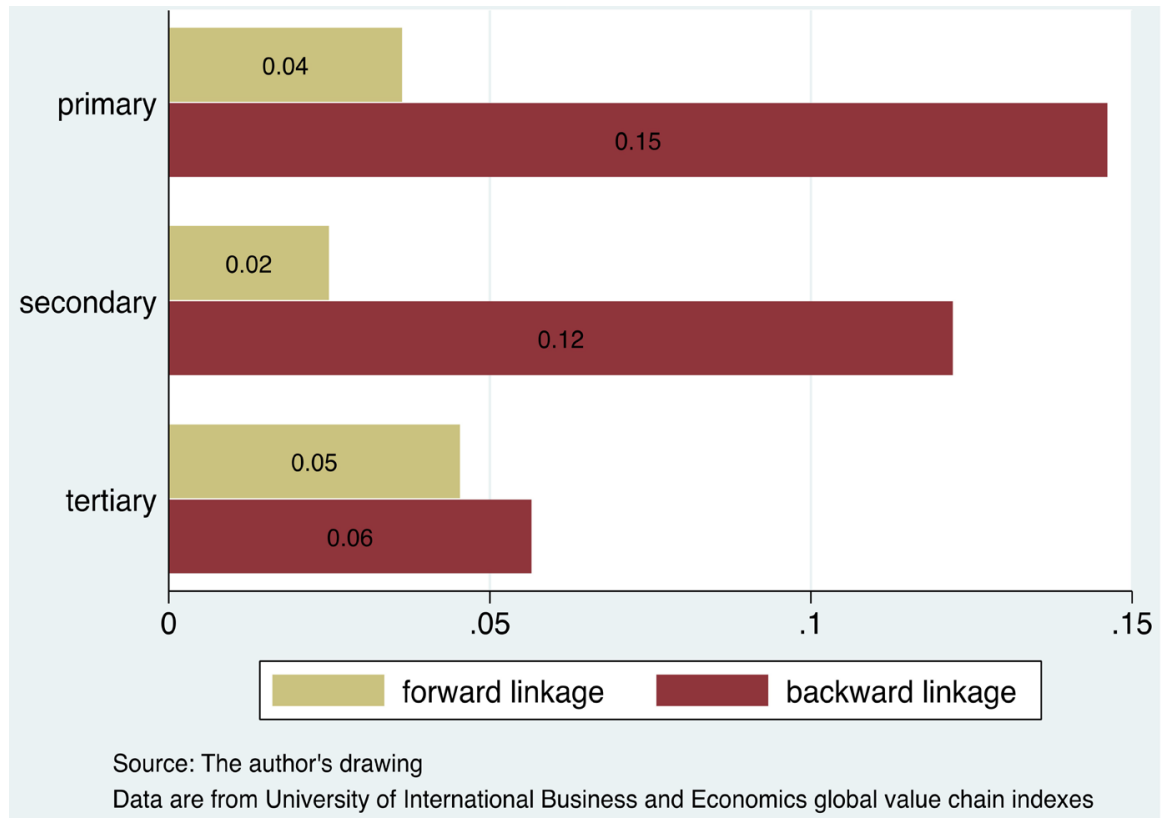

Figure 22. Complex GVC participation by sector (Central Africa).

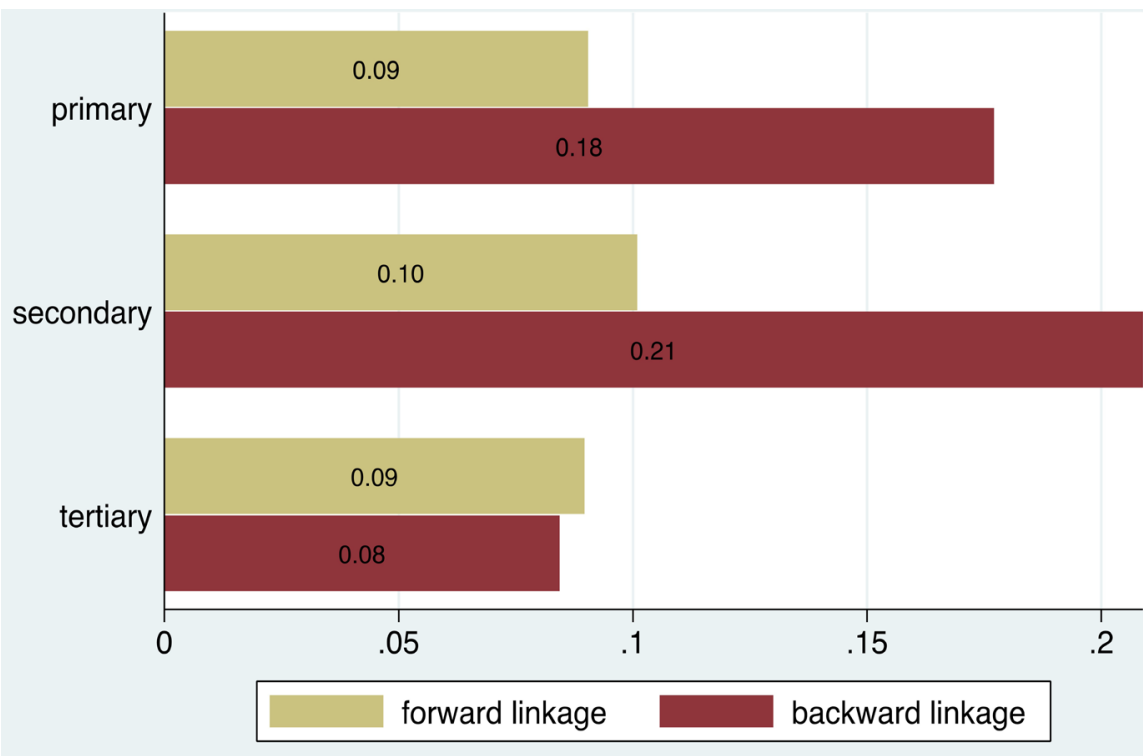

Source: The author's drawing

Data are from University of International Business and Economics global value chain indexes

Figure 23. Complex GVC participation by sector (Southern Africa). 


\section{Position in GVC}

In overall, Africa is on average weakly involved in downstream specialization as shown the GVC position in Table 1. This suggests that the activities of African economies in GVCs are oriented to the last stages of production. In addition, the average of total share of imported foreign value-added absorbed directly and indirectly (0.25) is larger than the mean of domestic factor content to export and consumed by direct and indirect partners abroad (0.20).

Through the graphical analysis, we deepen the GVC position of each country by region. In North Africa (Figure 24), one observes that Egypt is located in downstream specialization while Morocco and Tunisia are on the side of upstream activities. This finding reveals that the Egyptian economy represents a huge market for imported foreign inputs which are embodied in domestic intermediate goods to produce final products consumed at home. By contrast, Morocco and Tunisia are mainly exporters of domestic factor content.

In West Africa (Figure 25), the bulk of economies are engaged in downstream activities. Only Senegal and Burkina Faso are posited in upstream production. It should be noted that countries in downstream production absorb a large proportion of complex backward value-added whereas those in upstreamness tend to export domestic value-added.

Table 1. Descriptive statistics.

\begin{tabular}{ccccc}
\hline & mean & std.deviation & Min. & Max. \\
\hline GVC position & -0.04 & 0.90 & -3.07 & 3.48 \\
Total forward GVC participation & 0.20 & 0.20 & 0 & 1 \\
Total backward GVC participation & 0.25 & 0.18 & 0 & 1
\end{tabular}

Source: The author's calculation.

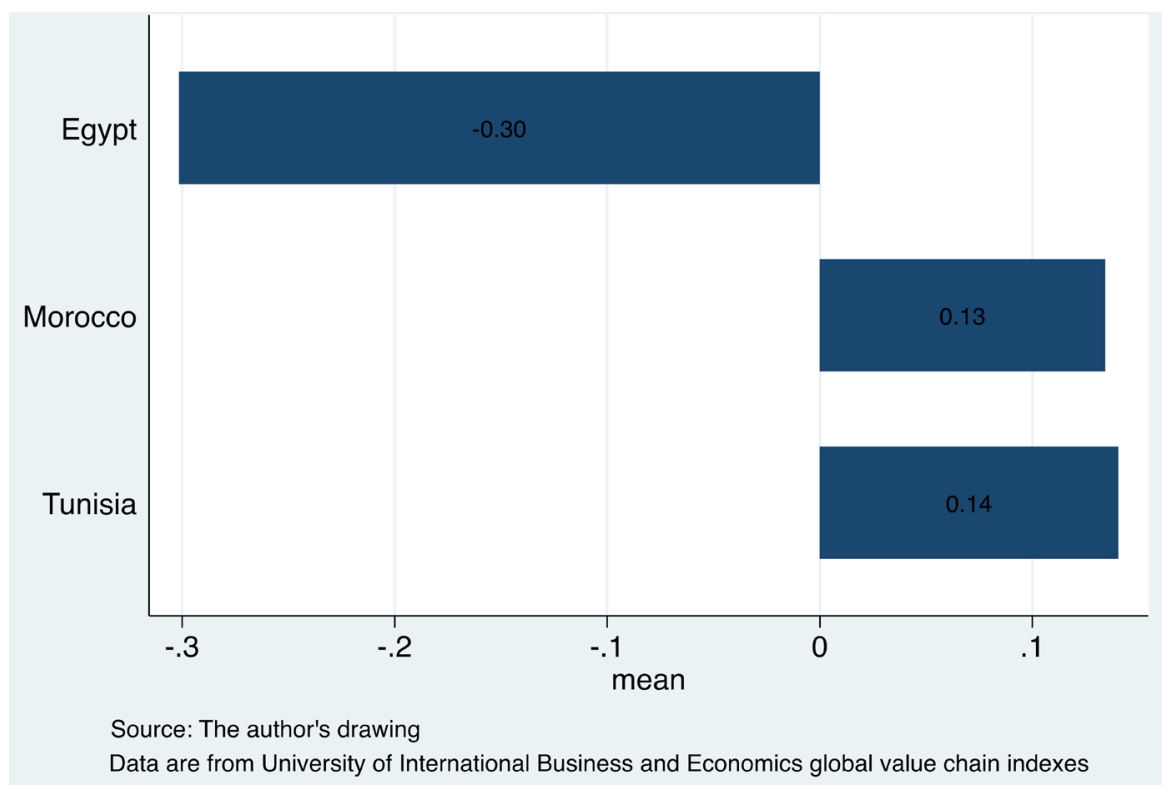

Figure 24. GVC position for African countries. 
With respect to East Africa (Figure 26), Uganda is the only country involved in upstream production while the rest of economies are engaged in downstream specialization. We observe that most countries in this region of Africa consume the largest proportion of value-added coming from abroad.

In Central Africa (Figure 27), Cameroon is mainly engaged in downstream production. In others terms, the economy of Cameroon imports a larger quantity of foreign valued-added for domestic consumption than it exports.

In Southern Africa (Figure 28), two countries (Malawi and Mozambique) out

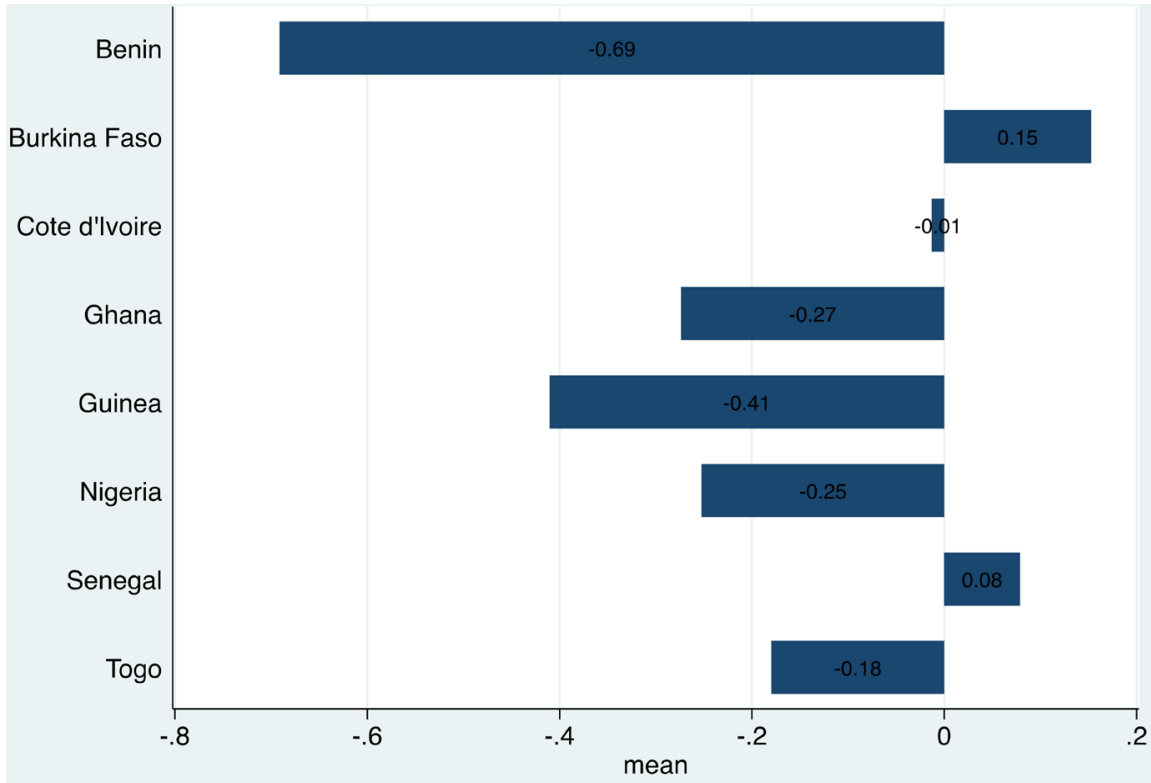

Source: The author's drawing

Data are from University of International Business and Economics global value chain indexes

Figure 25. GVC position for West African countries.

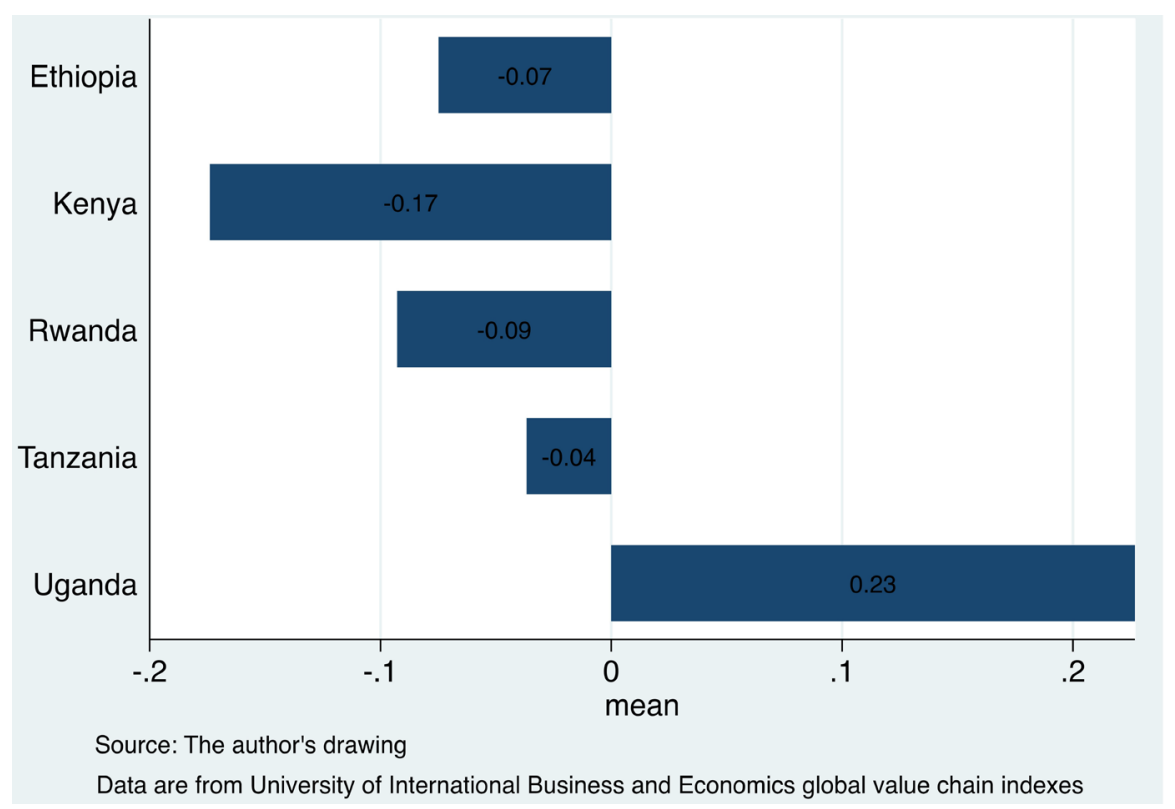

Figure 26. GVC position for East African countries. 


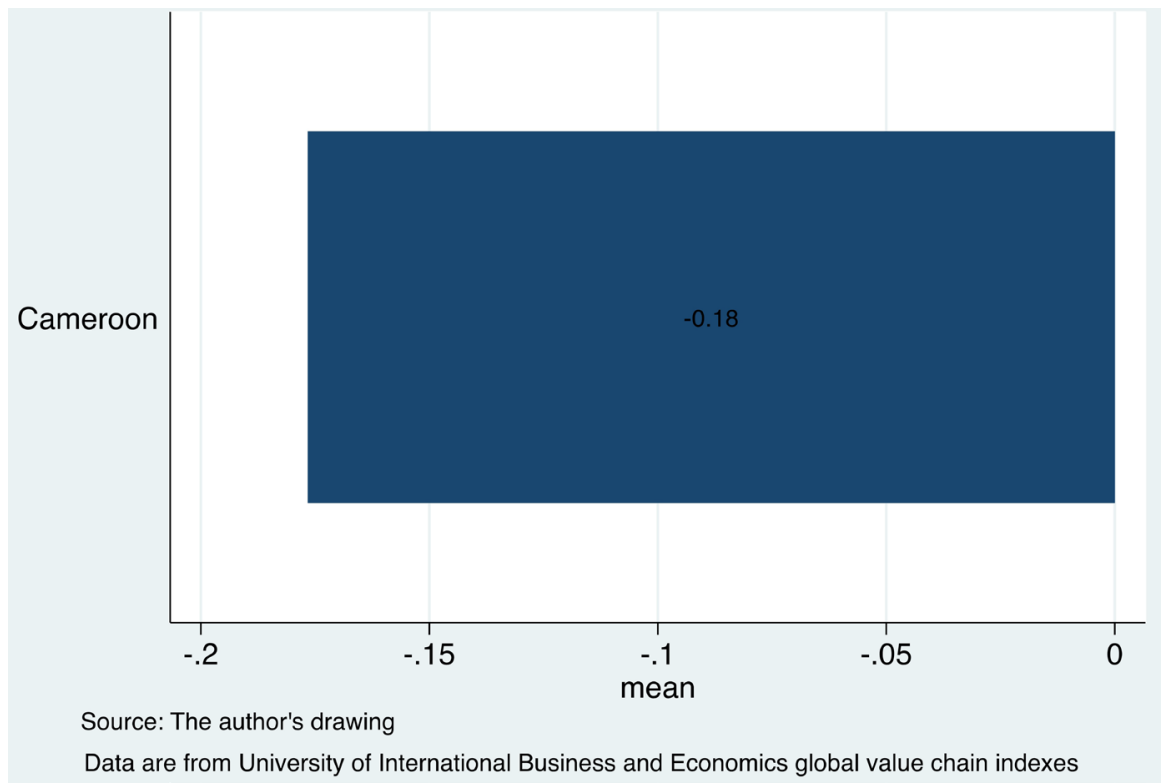

Figure 27. GVC position for Central African countries.

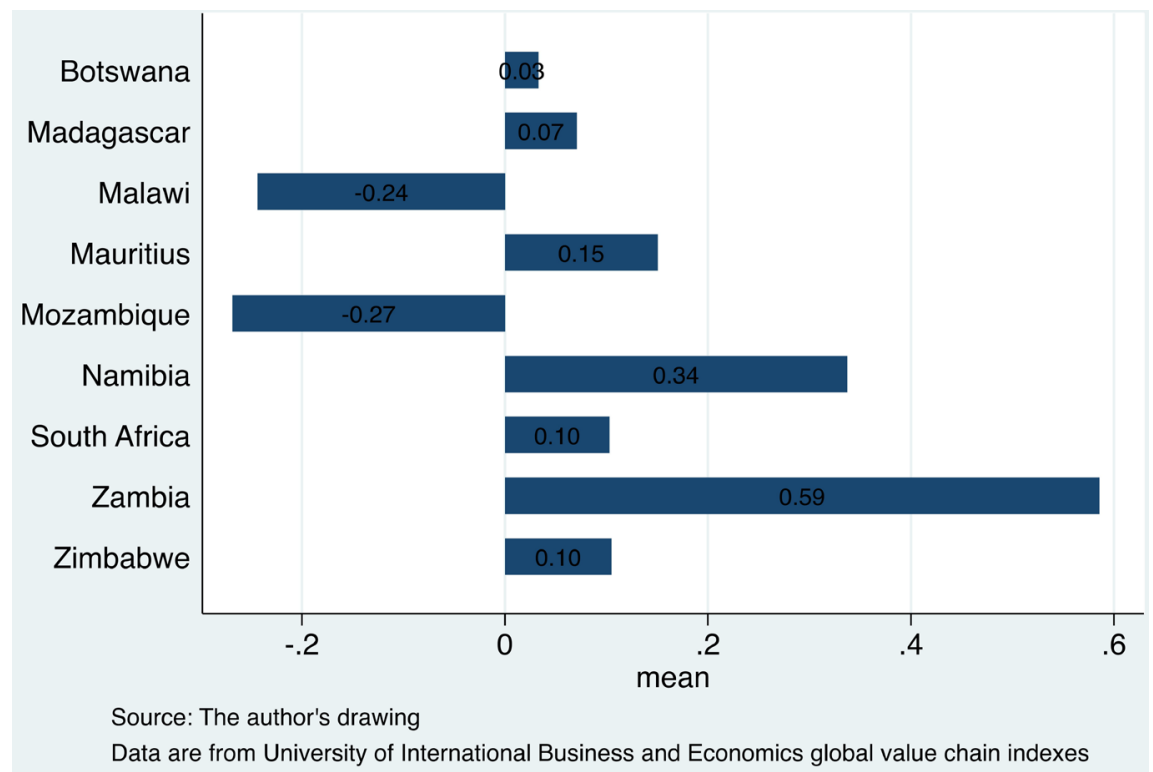

Figure 28. GVC position for Southern African countries.

of eight are involved in downstream specialization. This result shows that the economies of Southern Africa are mostly suppliers of value-added for the first stages of production to others economies specialized in downstream production.

\section{Conclusions}

The world economy is currently driven by the paradigm of trade in value-added commonly known as global value chains (GVCs). In such a context, scholars are striving to provide indicators to measure this new phenomenon. In this paper, we use a comprehensive database developed by Research Institute for Global Value Chains at University of International Business and Economics (UIBE) to 
investigate the patterns of value chain participation within African economies. To this end, we focus on three indexes: the first presents the simple GVC participation in forward and backward linkages; the second deals with the engagement in complex GVCs in forward and backward linkages as well; the last one highlights the countries' position along the value chain.

Our analysis points out that, on the whole, Africa exports more domestic value-added than it absorbs by importing foreign factor content in simple GVCs. By contrast, the continent consumes the larger proportion of value-added involved in complex GVCs. At the regional level, Southern Africa exports the highest share of domestic value-added to direct partners but North Africa is the top importer of foreign inputs in simple GVCs. When it comes to complex GVCs, the participation in forward linkage is insignificant within African regions. Conversely, the engagement in complex backward linkage is important in West Africa. At the sectoral level, Southern Africa is the higher participant in the primary sector for the simple forward and complex backward linkages. Central Africa is the most involved in the secondary sector for the simple forward participation but North Africa absorbs the greatest proportion of foreign inputs. For complex GVCs, West Africa is the top importer of intermediate goods coming from abroad. In regards to the tertiary sector, North Africa and Southern Africa display the highest level of participation in simple forward and backward linkages.

On the whole, African economies are engaged albeit weakly in downstream specialization. However, the analysis reveals some facts that deserve a deepened understanding. For instance, two countries with forward participation higher than backward participation, one is located in downstreamness and another in upstreamness. We observe a similar situation when the integration in backward linkage exceeds the one of forward participation.

\section{Acknowledgements}

I would like to express my deepest gratitude to Prof. Jiong Gong for his precious advice and comments.

\section{Conflicts of Interest}

The author declares no conflicts of interest regarding the publication of this paper.

\section{References}

[1] Allard, C., Kriljenko, J.I.C., Chen, W., Gonzalez-Garcia, J., Kitsios, E. and Treviño, J. (2016) Trade Integration and Global Value Chains in Sub-Saharan Africa: In Pursuit of the Missing Link. Departmental Paper No. 16/05, African Department, International Monetary Fund.

[2] Del Prete, D., Giovannetti, G. and Marvasi, E. (2018) Global Value Chains: New Evidence for North Africa. International Economics, 153, 42-54.

https://doi.org/10.1016/j.inteco.2017.03.002 
[3] Afdb, WEF, OECD, World Bank (2015) The Africa Competitiveness. Report 2015.

[4] Amador, J. and Cabral, S. (2014) Global Value Chains: A Survey of Drivers and Measures. Journal of Economic Surveys, 30, 278-301. https://doi.org/10.1111/joes.12097

[5] Bhatia, U.S. (2013) The Globalization of Supply Chains: Policy Challenges for Developing Countries. In: Elms, D.K. and Low, P., Eds., Global Value Chains in a Changing World, Chapter 13, 313-328.

[6] Dollar, D. (2017) Executive Summary. In: Global Value Chain Development Report 2017: Measuring and Analyzing the Impact of GVCs on Economic Development, 1-14.

[7] Gereffi, G. (2014) Global Value Chains in a Post-Washington Consensus World. Review of International Political Economy, 21, 9-37. https://doi.org/10.1080/09692290.2012.756414

[8] Gereffi, G. and Fernandez-Stark, K. (2016) Global Value Analysis : A Primer. Center on Globalization, Governance \& Competitiveness (Duke University), 2nd Edition, $1-34$.

[9] Grossman, G.M. and Rossi-Hansberg, E. (2008) Trading Tasks: A Simple Theory of Offshoring. American Economic Review, 98, 1978-1997. https://doi.org/10.1257/aer.98.5.1978

[10] Johnson, R. (2018) Measuring Global Value Chains. Annual Review of Economics, 10, 207-236. https://doi.org/10.1146/annurev-economics-080217-053600

[11] Koopman, R., Powers, W., Wang, Z. and Wei, S. (2010) Give Credit Where Credit Is Due: Tracing Value Added in Global Production Chains. NBER Working Paper 16426, NBER, Cambridge.

[12] Koopman, R., Wang, Z. and Wei, S. (2014) Tracing Value-Added and Double Counting in Gross Exports. American Economic Review, 104, 459-494. https://doi.org/10.1257/aer.104.2.459

[13] Wang, Z., Wei, S. and Zhu, K. (2013) Quantifying International Production Sharing at the Bilateral and Sector Levels. NBER Working Paper 19677, NBER, Cambridge.

[14] Wang, Z., Wei, S., Yu, X. and Zhu, K. (2017a) Measures of Participation in Global Value Chain and Global Business Cycles. NBER Working Paper No. 23222, NBER, Cambridge.

[15] Wang, Z., Wei, S., Yu, X. and Zhu, K. (2017) Characterizing Global Value Chains: Production Length and Upstreamness. NBER Working Paper No. 23261, NBER, Cambridge.

[16] Antras, P., Chor, D., Fally, T. and Hillberry, R. (2012) Measuring the Upstreamness of Production and Trade Flows. American Economic Review, 102, 412-416. https://doi.org/10.1257/aer.102.3.412

[17] Antras, P. and Chor, D. (2013) Organizing the Global Value Chain. Econometrivca, 81, 2127-2204. https://doi.org/10.3982/ECTA10813 


\section{Appendix: Decomposing GDP and Final Goods Production by Country or Sector ${ }^{6}$}

Forward linkage-based: Producer perspective

Which types of GDP production activities belong to GVCs?

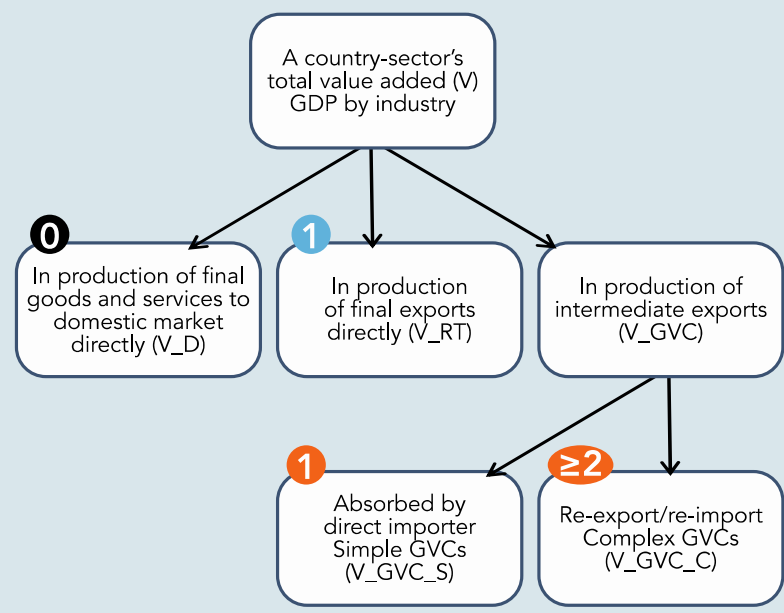

Backward linkage-based: User perspective

Which types of final goods production belong to GVCs?

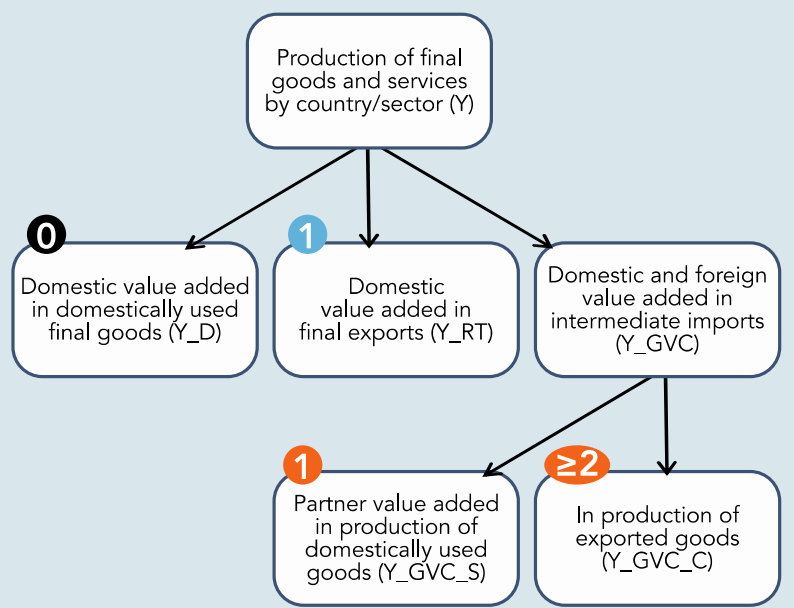

${ }^{6}$ The description of decomposing GDP and final goods production by country or sector into different types of activities belonging to global value chain or not comes from Global Value Chain Development Report 2017: Measuring and Analyzing the Impact of GVCs on Economic Development (p. 42). 